\title{
SCIENTOMETRIC ANALYSIS OF PSYCHOLOGICAL INTERVENTIONS BASED UPON THE USE OF HYPNOSIS
}

\author{
MIGUEL ÁNGEL MUÑOZ-LÓPEZ*, MARÍA DEL ROCÍO HERNÁNDEZ-POZO** \\ UNIVERSIDAD NACIONAL AUTÓNOMA DE MÉXICO, FES IZTACALA, ESTADO DE MÉXICO, MÉXICO
}

Recibido: 15 de Septiembre de 2015

Aprobado: 11 de Marzo de 2016

Para referenciar este artículo:

Muñoz López, M. \& Hernández Pozo, M. (2016). Scientometric analysis of psychological interventions based upon the use of hipnosis. Revista Iberoamericana de Psicología: Ciencia y Tecnología, 9 (1), 85-94

\begin{abstract}
Hypnosis is a therapeutic technique that has developed for centuries, and every time with greater clinical and scientific weight. Currently, hypnosis constitutes a solid support method for treatments against chronic pain and for emotion control under situations that generate fear and anxiety -such as surgery or other type of phobias-, so it is presented as an alternative to the use of medicine/drugs by health specialists. On the other hand within the field of behavioral sciences, apart from controlling fear and anxiety responses, hypnosis serves as support to the various cognitive behavioral techniques by facilitating their assimilation and development. This work presents a scientometric study of the research done on hypnosis over the last fifteen years, from publications -in Spanish and English-in specialized journals, indexed in SCOPUS (a specialized international bibliometric database). The contemporary applications of hypnosis are presented and critically discussed; as well as the fields in which its application has proven successful; its limitations; the research networks generated within the time of the study; plus, probable projections for future research are also mentioned. Key words: Hypnosis; cognitive; behavioral; therapy; treatment; extinction; psychology; research; intervention; sleep; anxiety; stress; relaxation; pain; learning.
\end{abstract}

\section{ANÁLISIS CIENCIOMÉTRICO DE INTERVENCIONES PSICOLÓGICAS BASADA EN EL USO DE LA HIPNOSIS}

\begin{abstract}
Resumen
La hipnosis es una técnica que se ha desarrollado con el paso de los siglos, cada vez con mayor peso clínico y científico. Actualmente la hipnosis constituye un método sólido de apoyo a tratamientos contra el dolor crónico y control de emociones ante situaciones que generan miedo y ansiedad como la cirugía u otro tipo de fobias, por lo cual se presenta como una alternativa al uso de fármacos por los especialistas en salud. Por otro lado dentro del campo de las ciencias del comportamiento, además de controlar respuestas de miedo y ansiedad, la hipnosis sirve como apoyo a las diversas técnicas cognitivo conductuales, al facilitar su asimilación y desarrollo. Esta investigación presenta un estudio cienciométrico de las investigaciones realizadas en los últimos quince años acerca de la hipnosis, a partir de publicaciones en revistas especializadas publicadas en español y en inglés, que están indizadas en SCOPUS, una base bibliométrica internacional especializada. Se presenta y discute de manera crítica las aplicaciones contemporáneas de la hipnosis, los campos en que ha tenido éxito su aplicación, sus limitaciones, las redes de investigación generadas durante el tiempo acogido por el estudio y se mencionan proyecciones probables para estudios futuros.

Palabras clave: Hipnosis; cognitivo; conductual; tratamiento; extinción; psicología; investigación; intervención; sueño; ansiedad; estrés; relajación; dolor; aprendizaje.
\end{abstract}

* Co-Investigador Lic. Miguel Angel Muñoz López. Docente. Centro de Actualización del Magisterio, Durango. miguelangel@arrayansoft.com

* Co-investigadora Dra. María del Rocío Hernández Pozo. Directora de Investigación, Docente. Universidad Nacional Autónoma de México, Centro Regional de investigación multidisciplinaria, estudios de equidad de género. Universidad Nacional Autónoma de México, FES Iztacala, Human Learning research project. rochpoz@co-educa.org. 
According to Jensen (2011) the use of hypnosis as a therapeutic or healing method has ancient roots, as ancient as the Egyptian sleep temples. Yet, Franz Mesmer was the pioneer in the study of the phenomenon as a healing method. With time this technique received more recognition, especially through Freud's and Brehuer's work on psychoanalysis, a discipline in which hypnosis is conceived as a key technique to support psychological therapy, to reach catharsis and abreation. Later on, this method was further developed by Milton Erickson.

The American Psychological Association -APA- defines hypnosis as a guided induction procedure that works with the patient's imagination, that encourages responses to the therapist's suggestions (which may involve alterations on perception, sensation, emotion, thinking and/or behavior) for their further evaluation; Hypnosis can also be carried out by a single person, in which case it is called self-hypnosis (APA, 2005).

The method of hypnosis varies by patient and the purpose of its use via scripts, however not all people are susceptible to hypnotic suggestion (APA, 2005). In order to assess this feature some standardized tests were designed to measure the subject's susceptibility to hypnosis, such as the Stanford Hypnotic Susceptibility Scale (SHSS) and the Harvard Group Scale of Hypnotic Susceptibility (HGAHS).

Hypnotic induction and its positive use to promote health are still under investigation, findings about new treatments and research based upon this procedure gradually emerge, and hypnosis proves to be an effective tool to improve therapy or support psychological processes that might have an effect on brain functionality and cognitive structures of individuals.

The effective use of hypnosis to improve patients' health has been researched through/employing quantitative and qualitative approaches, using experimental-cuasiexperimental and case study methods respectively, with these studies resulting in an improvement of the quality of life of patients with medical and/or chronic problems involving degenerative procedures.

Within the field of behavioral sciences, hypnotic induction reduces anxiety and fear responses, in addition to supporting various cognitive behavioral techniques, and encouraging patient adherence (Smith, 2011).

The purpose of the present research was to create a map of the researches that had used hypnotic methodology in different fields of science, in order to account for the effectiveness of this procedure in applied sciences, as well as to identify key areas of knowledge where this procedure is used, the type of problems solved, as well as the peculiarities of its use.

\section{Method}

A bibliographical research was conducted on the SCOPUS database. The the collections "Social Sciences and Humanities" and "Health Sciences" were reviewed, specifically their publications made during a period of 11 and a half years, from January 2002 to June 2013. The key words used for the search were: "hypnosis", "cognitive", "behavioral", "therapy" and "intervention" to encompass all empirical studies using this technique for application purposes. 4 records with languages other than English and Spanish were discarded given that specific details concerning their methodology and findings were not available; also publications in book format were excluded in order to unify the selection criteria for peer evaluation, given that journals usually are subjected to a stricter peer review process. Under these guidelines 54 articles that met these criteria were obtained. The analysis of results was carried out based on the NodeXL network software aided by the analysis engine provided by the SCOPUS search engine.

The NodeXL network software is an open-source and free template for Microsoft ${ }^{\circledR}$ Exce ${ }^{\circledR}$ developed by The Social Media Research Foundation ${ }^{\circledR}$. This program supports the correlation between variables that are captured in columns and then a graphic is generated where such correlation is shown. This study involves a series of steps, concluding in a graphic data demonstration, these steps are: papers review, capture of variable data, disposal of variables that are not shown in most of the papers, capture data on NodeXL, and capture of graphic representations.

\section{Results}

The results are organized using the NodeXL collaborative networks for the countries home of the 54 articles under study.

In figure 1, for each collaborative network the vertices represent individual researchers (some of who are represented in the network through their pictures obtained by means of a public electronic medium, either institutional or personal) or show the main authors represented by a triangle and co-authors by circles; co-authors of more than one publication are represented by bigger circles. The nationality of the main author or leader stands next to his or her name; also, data concerning the number of citations up to the date when the research was finalized (June 2013), are shown in brackets. These citations had been made by other authors who had also published articles in journals indexed by the Dutch based SCOPUS system.

Figure 1 shows that most of the articles were from the U.S. - a total of 28 , more than $50 \%$ of the grand totalfollowed by Canada and England -with 5 and 4 articles 
respectively-. The figure also shows that the article with more coauthors participating in the research was from the U.S. - with 23 authors; additionally only 4 countries were registered with 4 or more authors per study; the network leadered by Montgomery-Schnur is noteworthy because it was conformed by researchers involved in more than one paper on the topic. On the same line, the network headed by Kirsch, stands out due to its participation in two articles with collaborations from different nationalities: England and USA. Finally the article that received the highest number of citations was written by a team headed by Sim and Adams from the UK, on the topic of nonpharmacological interventions for fibromyalgia, with 167 citations from journals indexed by SCOPUS.

The authors with more citations were from Canada (Savard, Simard, Ivers and Morin on therapy for insomnia in breast cancer patients, with 133 citations) and from U.S.A. (the article by Richardson and Rothstein with 92 citations, was a meta-analysis of intervention programs for the occupational stress).

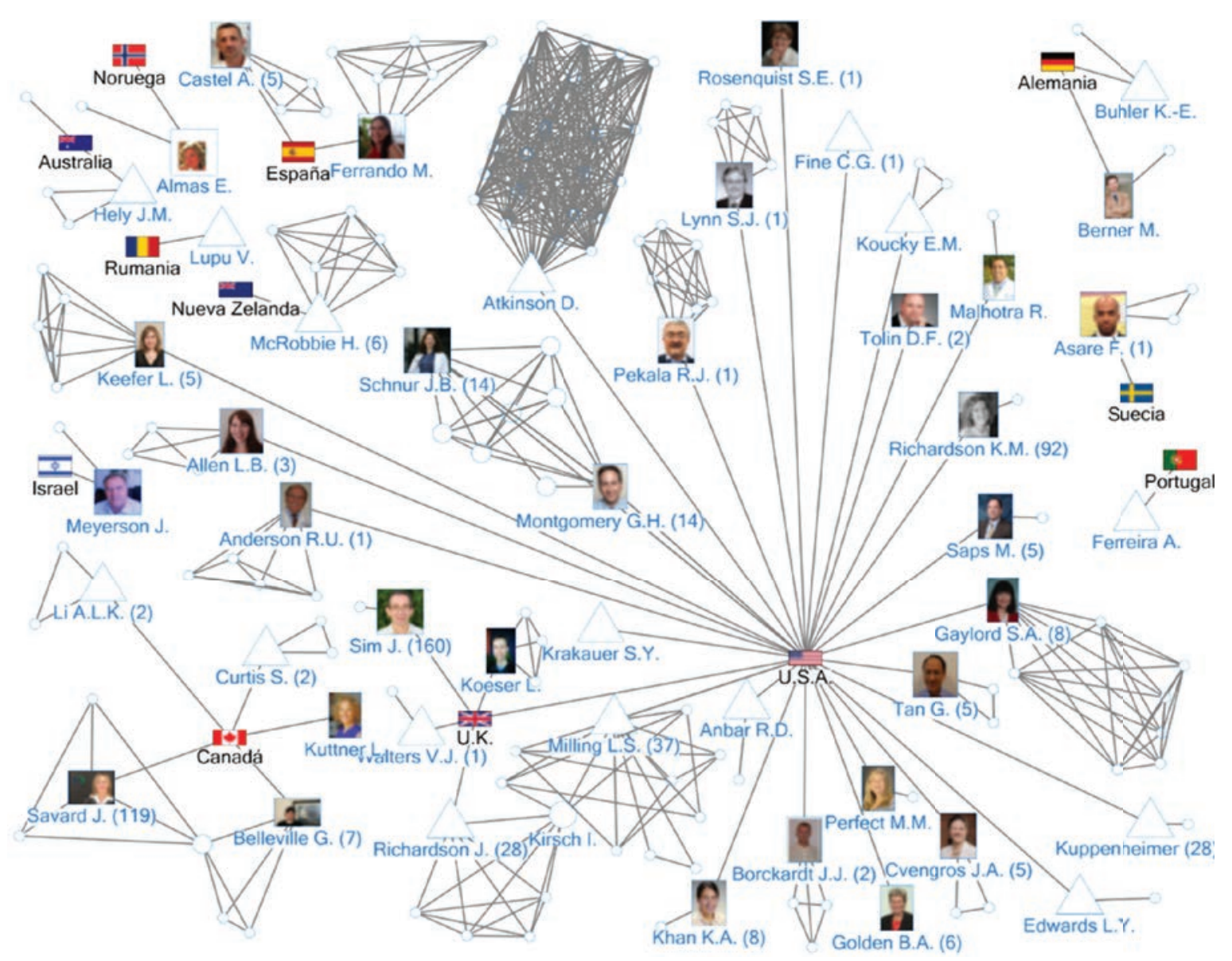

Figure 1. Network analysis based on author variables, country and number of citations.

Other aspects are highlighted in figure 2. Journals with most articles on the subject of hypnosis are specialized ones, like the American Journal of Clinical Hypnosis with 7 articles and Contemporary Hypnosis with 4 . The remaining 43 items were published among 37 journals directed to more general subjects. For about $30 \%$ of the literature under study, the application of hypnosis in the medical field predominated, versus its applications in the behavioral field. This figure also facilitates the visualization of the main authors participating in more than one paper, as was the case of Montgomery and Milling. 


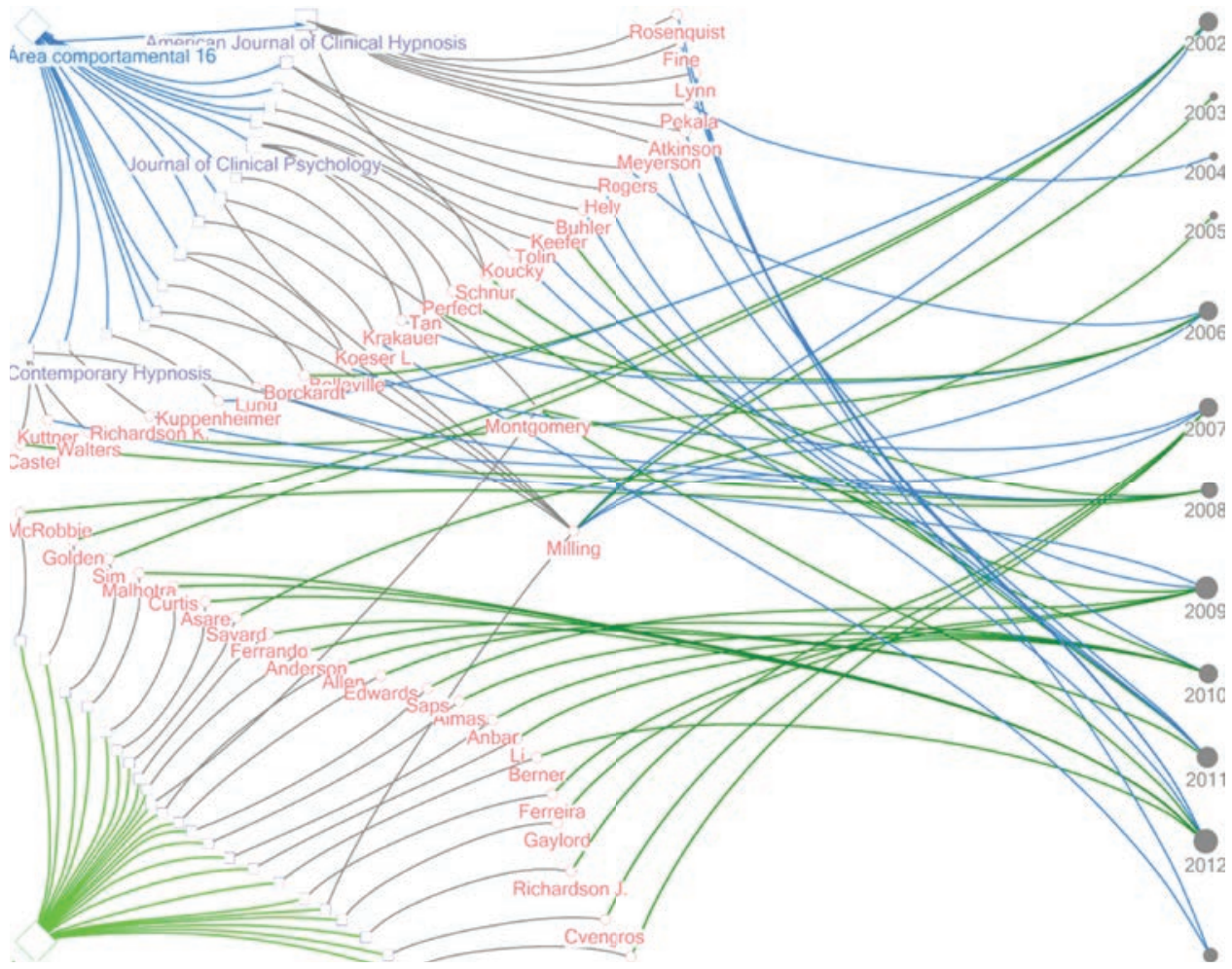

Figure 2. Network analysis based on the variables: field of the study, year of publication and main author of the simple of articles on hypnosis interventions.

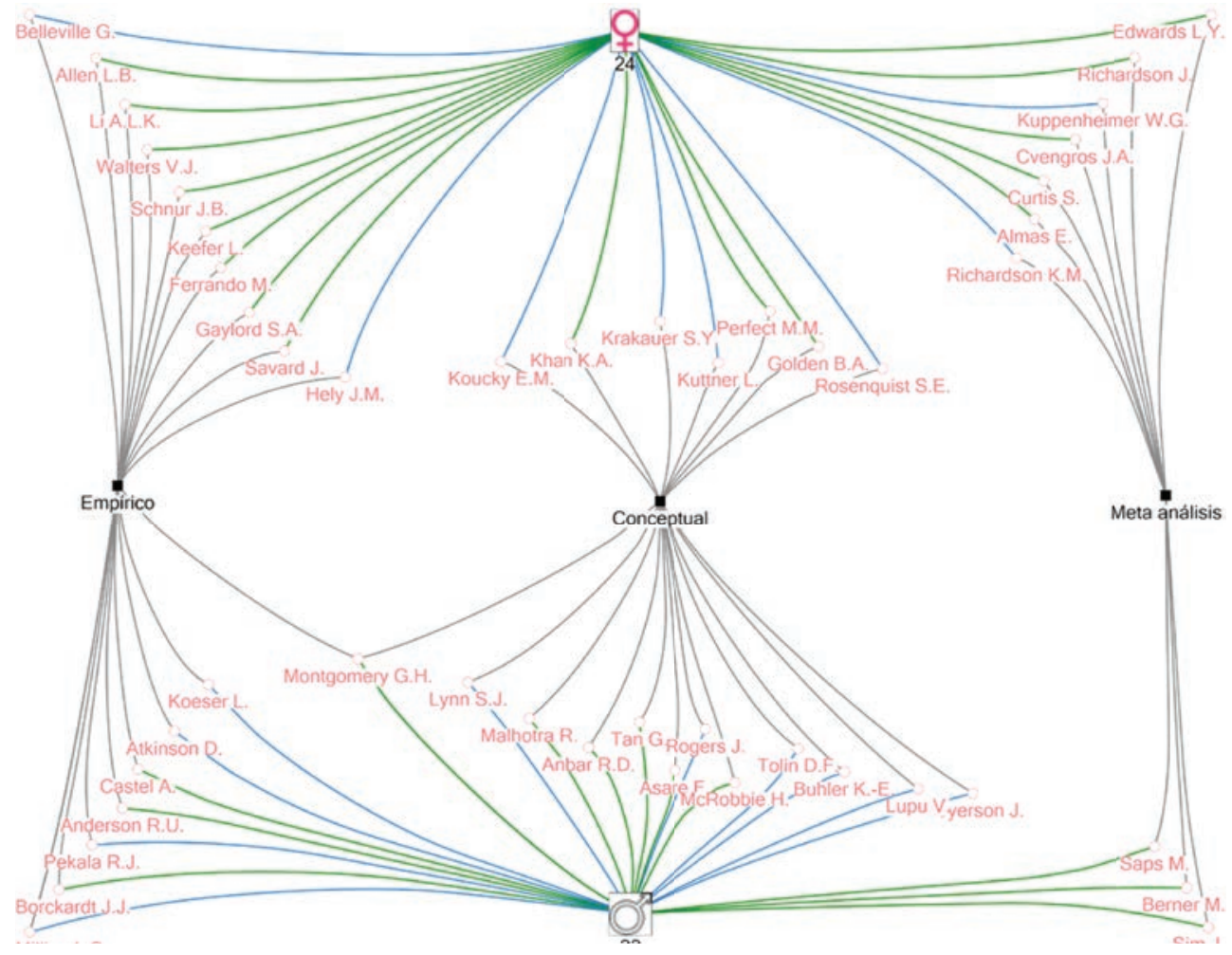

Figure 3. On hypnosis interventions organized by sex and type of study. 
On the other hand, figure 3 organizes articles based on the sex of the main researcher and the type of research. Regarding the first category, there was relative equality between the number of researchers in both groups; differences based on sex and type of study were: 2.3 to 1 in the number of meta-analyzes studies by female researchers; the graphic was different for the publications focused on conceptual analyzes, as 12 papers of that type were coor- dinated by male authors and 7 conceptual articles headed by female authors. Finally, no significant difference was found in the empirical articles since the distribution was equal between the sexes, as seen in figure 3 .

When contrasting the studies of hypnosis in general to investigations employing self-hypnosis, figure 4 shows that self-hypnosis was taken into account only in $9.25 \%$ of the interventions.

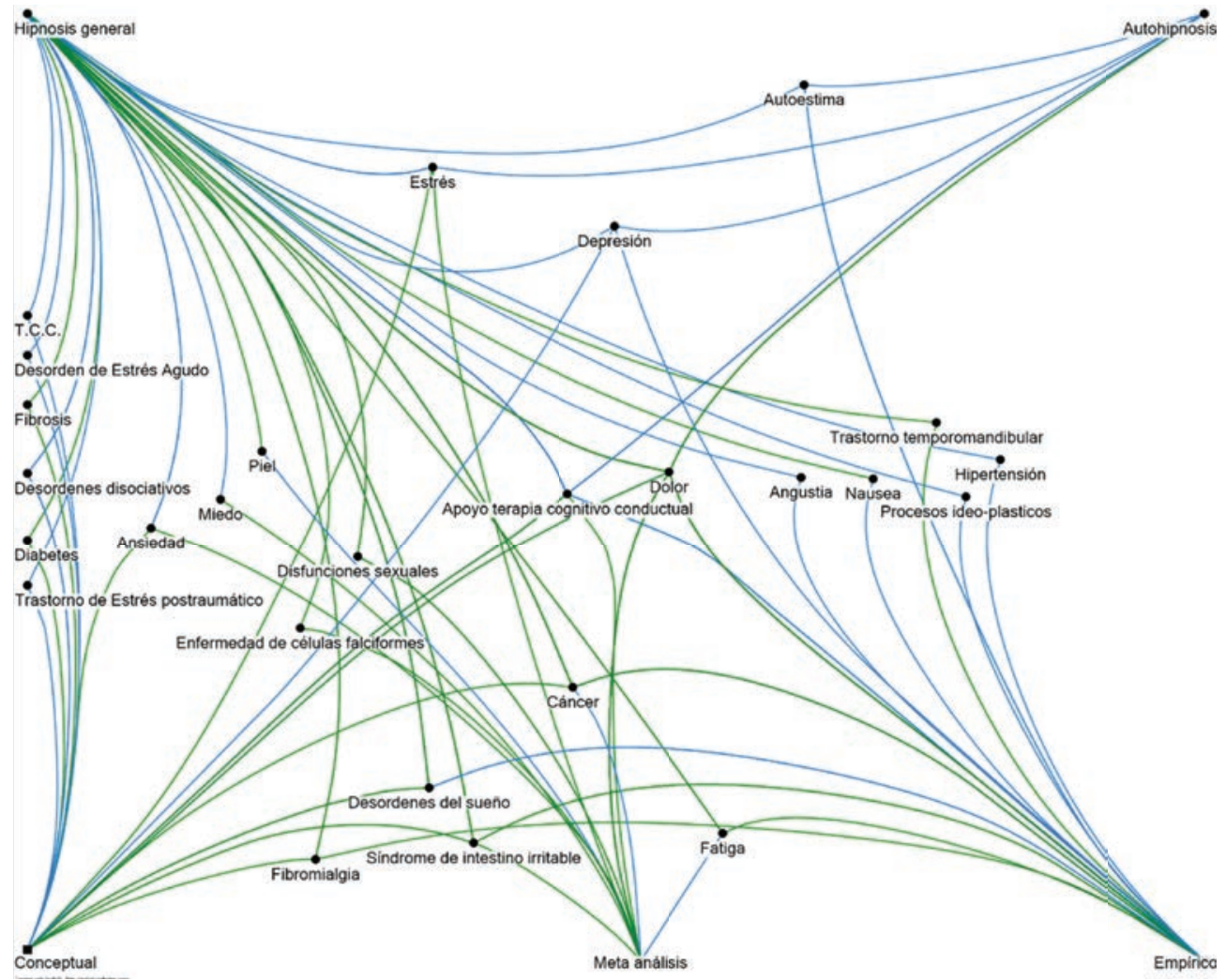

Figure 4. Analysis of networks organized by type of hypnosis, focus of the study and treatment goal.

There was no significant difference between the number of articles devoted to the different focuses of the studies: conceptual meta-analysis and empirical. It is important to mention that both, research on pain and hypnosis, as a support tool for cognitive behavioral therapy were dominant among the subject matters of the articles, in the sense that they employed hypnosis in general and self-hypnosis, plus, both represented conceptual, meta-analysis and empirical studies. Figure 4 represents both topics in its central portion as vertices where lines coming from different directions concur.
Finally, regarding the reported outcomes of such interventions, only one article points out the failure of the intervention (in the upper left corner of figure 5). The aim of that article was focused on reduction of stress and pain; while $18.5 \%$ of the articles did not offer a conclusive solution; $79 \%$ of the papers reported success, which talks about a significant positive effect of hypnotherapy on those problems. 


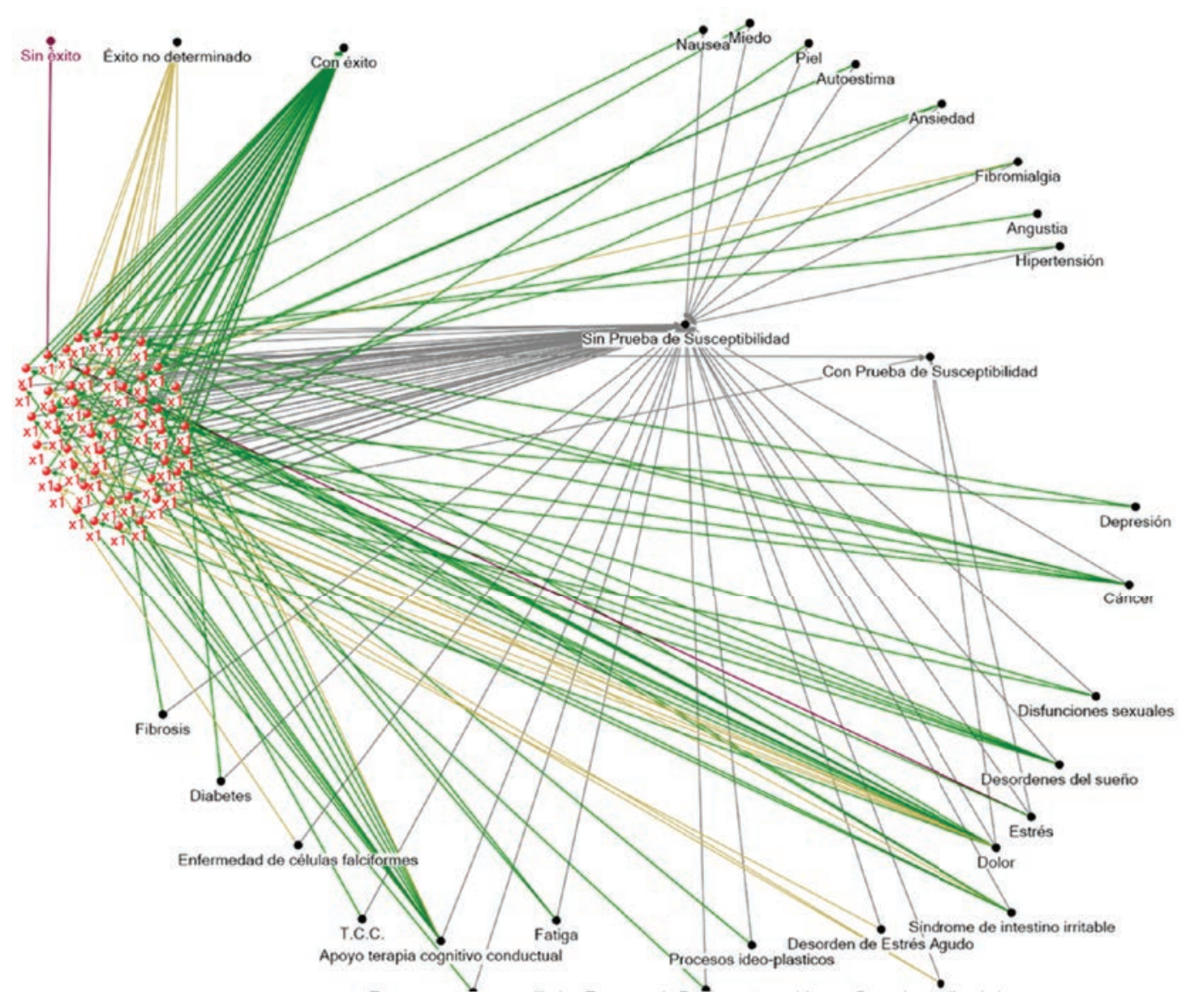

Figure 5: Network analysis based on the outcome of the hypnotic intervention, use or not of susceptibility tests and treatment goal. X1 stands out as the unit of measurement.

Studies on cancer, pain, and support for cognitive behavioral therapy and sleep disorders had the highest number of investigations and associated successes. Figure 5 shows the distribution of the articles in this light. In this figure it is shown that over $90 \%$ of the research did not control for susceptibility to hypnosis, this is important to highlight because about $20 \%$ of people cannot be hypnotized under normal conditions and not clarifying this aspect at the beginning of the study constitutes a methodological flaw for the proper interpretation of the findings in hypnotic research.

\section{Discussion}

This research supported by NodeXL software offers a scientometric analysis describing the main tendencies of current studies on hypnosis interventions and its range of applications. Results indicate that hypnosis has medical and psychological applications to support medical processes such as the replacement of general anesthesia in children or allergic patients, also in the phantom limb treatment. It also helps with anxiety reduction before surgical procedures; regarding health, hypnosis has been used to improve the quality of life in patients with chronical diseases such as cancer and other illnesses involving chronic pain.

The positive outcome create conditions for open-mindedness towards new cognitive procedures that modify negative behaviors and establish new and improved concepts of self-reliance and self-esteem; this in turn, is directly linked with cognitive behavioral therapy, where hypnosis has been proven to be a supportive factor for improving the implementation of different therapy methods tailored to cope specific problems suffered by patientsm and in some cases its positive results remain after months.

Hypnosis can be used as a therapy by itself but the results show more efficiency when it's used along with another cognitive intervention, the most common use is before anxiety and phobia situations. It also shows positive results in the improvement of cognitive abilities as stress coping, behavior self-regulation, self-esteem improvement, etc. Finally it is a phenomenon that affects both aspects 
cognitive and physical in interventions as the stuttering treatment.

In the research methodology aspect both approaches, qualitative and quantitative, are used. In the quantitative approach experimental and quasi experimental research with control groups were identified. Only in 20 of 51 reviewed studies the use of pre-evaluation and post-evaluation were mentioned.

Currently research on hypnosis, is not standardized yet, in situations of case study research, being qualitative in nature, standarization can be avoided to some extent, but as a methodological measure, it would be advisable to use pre-and post-intervention evaluations with hypnosis, in order to use a robust approach that would aid further interpretations of the findings.

About 8 out of 10 people are susceptible to hypnosis, theoretically this leaves out $20 \%$ of the population that cannot be hypnotized under normal conditions, a percentage high enough to be neglected. The middle of the past century tests had been developed to measure susceptibility to hypnosis and imaginative absorption -a variable associated to suggestibility with good reliability.

Among the test that had been used for this purpose are the Stanford Hypnotic Susceptibility Scale (Weitzenhoffer \& Hilgard, 1959, 1962), the Harvard Group Scale of Hypnotic Susceptibility (Shor \& Orne, 1962) and the absorption ability test (Tellegen, 1979). Even when these measures of hypnotic susceptibility are available, this research shows that most of the studies reviewed did not use them. When susceptibility to hypnosis is ignored, at least 2 out of 10 subject's failures could be attributed to these methodological flaw, and although studies generally report successful results, these results are not accurate due to the lack of the use of susceptibility and imaginative absorption measures. When susceptibility is taken into account, other extraneous variables are controlled or taken into perspective, such as the type of technique (classical, Ericksonian, etc.) and the skills of the hypnotist, given that only subjects that are susceptible to hypnosis might be selected to participate in studies using hypnotic treatments.

Another aspect worth noting is that despite the psychological nature of hypnosis, most studies focused on medical applications, due to their recognized practical effects, but it is worrying that this resource perhaps could be wasted by not being taken into account in psychological interventions, as it can give relevant information about the cognitive and physiological processes in people's behavior.

The study of hypnosis has produced results that justify its use, but as noted above, hypnosis is not yet fully established, is a therapeutic tool that has not been fully exploited. The revised research, in addition to providing data on successful practices offers new treatment and research hypothesis; some of the topics identified during the period covered by this research include: a) cognitive and / or physiological characteristics of subjects with and without susceptibility to hypnosis, b) methods of virtual reality hypnosis and its effect on people not susceptible to traditional hypnosis, c) study of detached physiological functions related to cognitive structures, their uses and effects, d) study of split-off cognitive structures during hypnosis and phenomenological development.

The results of this research could be complemented by data found on types of hypnosis like classic, auto hypnosis or Ericksonian, however this information was not explicit in all cases, so a goal for future research would be to consider this variable as a key to relate the level of success or failure of the reported results.

The study of hypnosis holds promising hypotheses, this type of therapy offers both theoretical and practical knowledge. The revised cases provide data of the use of hypnosis as support technique for clinical and health psychological therapy.

In the theoretical field, hypnosis is presented as a probable instrument to separate cognitive processes that naturally work as a whole, as it's the case of executive functions. According to some papers reviewed in this document, a functional dissection has been detected between the monitoring control records and executive intelligence cognitive processes under hypnotical influence (Egner, Jamieson \& Gruzelier, 2005); the separation of the cognitive and the associated physical processes can also be studied, this is explained in a paper (Sebastiani, D'Alessandro, Menicucci, Ghelarducci \& Santarcangelo, 2006) that found that in a hypnotical induction the patient could experience cognitive fear but his body didn't show any relative organic signals as sweating and increased heart rate. Data obtained in future research may help to clarify aspects of brain and cognitive functioning, it could support the treatment of situations where physical responses could not be confronted, by means of hypnotherapy people would face only cognitive difficulties before a stimulus that also provokes physiological responses (this phenomenon is already registered in some research).

This research highlights the need to measure the subjects' susceptibility to hypnosis, this is a basic step to reach interpretations free from extraneous variables. On this point it is important to investigate how to improve hypnotherapy among people who show low suggestibility or low imaginative capacity. The study by Wiechman-Askay, Patterson \& Sharar (2009) on hypnotherapy administered by the techni- 
que of virtual reality offers encouraging preliminary results in this direction both in laboratory and clinical studies. The latter studies were carried out with victims of severe burns and other patients suffering from chronic pain, as well as with people with different health problems who are less susceptible to the traditional form of hypnosis, or people whose imaginative capacity is reduced, compromised or limited for some other reason. It is worth mentioning that some drawbacks from using virtual reality hypnotherapy are its high cost and the argument held by some authors that traditional hypnosis has much positive effects. Another perspective about hypnotic susceptibility is the cognitive abilities model that consider this phenomenon as a cognitive process that can be voluntary or involuntary and the individual can learn hypnotical abilities in the same way that can learn another cognitive ability.

\section{References}

Allen, L. B., Tsao, J. C. I., Hayes, L. P., \& Zeltzer, L. K. (2011). Peer mentorship to promote effective pain management in adolescents: Study protocol for a randomised controlled trial. Trials, 12, art. No. 132. Aviable via http: //dx. doi.org/10.1186/1745-6215-12-132

Almås, E., \& Landmark, B. (2010). Non-pharmacological treatment of sexual problems - A review of research literature 1970-2008. Sexologies, 19 (4), 202-211. Aviable via http://dx.doi.org/10.1016/j.sexol.2010.09.011

American Psychological Association. [APA] (2005). Hypnosis. Recuperado de http://www.apa.org/topics/hypnosis/index.aspx

Anbar, R. D., \& Murthy, V. V. (2010). Reestablishment of hope as an intervention for a patient with cystic fibrosis awaiting lung transplantation. Journal of Alternative and Complementary Medicine, 16 (9), 1007-1010. Aviable via http://dx.doi.org/10.1089/acm.2010.0107

Anderson, R. U., Nagy, T. F., Orenberg, E. K., Morey, A., \& Glowe, P. (2011). Feasibility trial of medical hypnosis and cognitive behavioral therapy for men with refractory chronic prostatitis/chronic pelvic pain syndrome. UroToday International Journal, 4 (4), S.P. Available via http: // dx.doi.org/10.3834/uij.1944-5784.2011.08.02

Asare, F., S $\square$ rsrud, S., \& Sim $\square$ n, M. (2012). Meditation over medication for irritable bowel syndrome? On exercise and alternative treatments for irritable bowel syndrome. Current Gastroenterology Reports, 14 (4), 283-289. DOI: 10.1007/s11894-012-0268-2

Askay, S., Patterson, D., \& Sharar, S. (2009). Virtual reality hypnosis. Contemporary Hypnosis, 26 (1), 40-47. Aviable via: http://dx.doi.org/10.1002/ch.371

Atkinson, D., lannotti, S., Cozzolino, M., Castiglione, S., Cicatelli, A., Vyas, B., ..., \& Rossi, E. (2010). A new bioinformatics paradigm for the theory, research, and practice of therapeutic hypnosis. American Journal of Clinical Hypnosis, 53 (1), 27-46.
Belleville, G., Guay, C., Guay, B., \& Morin, C. M. (2007). Hypnotic Taper With or Without Self-Help Treatment of Insomnia: A Randomized Clinical Trial. Journal of Consulting and Clinical Psychology, 75 (2), 325-335. Aviable via http://dx.doi.org/10.1037/0022-006X.75.2.325

Berner, M., \& Günzler, C. (2012). Efficacy of Psychosocial Interventions in Men and Women with Sexual Dysfunctions-A Systematic Review of Controlled Clinical Trials: Part 1-The efficacy of psychosocial interventions for male sexual dysfunction Berner and Günzler Psychosocial Interventions in Male Sexual Dysfunction. Journal of Sexual Medicine, 9 (12), 3089-3107. Aviable via http:// dx.doi.org/10.1111/j.1743-6109.2012.02970.x

Borckardt, J. J., Greenman, R., Simon, V., \& Cardeña, E. (2002). Case study examining the efficacy of a multi-modal psychotherapeutic intervention for hypertension. International Journal of Clinical and Experimental Hypnosis, $50(2), 189-201$.

Bühler, K.-E., \& Heim, G. (2011). Etiology, pathogenesis, and therapy according to Pierre Janet concerning conversion disorders and dissociative disorders. American Journal of Psychotherapy, 65 (4), 281-309.

Castel, A., Salvat, M., Sala, M., \& Rull, M. (2009). Cognitive-behavioural group treatment with hypnosis: a randomized pilot trial in fibromyalgia. Contemporary Hypnosis, 26 (1), 48-59. Aviable via http://dx.doi.org/10.1002/ ch. 372

Cvengros, J. A., Harper, D., \& Shevell, M. (2007). Pediatric headache: An examination of process variables in treatment. Journal of Child Neurology, 22 (10), 1172-1181. Aviable via http://dx.doi.org/10.1177/0883073807305786

Curtis, S., Wingert, A., \& Ali, S. (2012). The Cochrane Library and procedural pain in children: An overview of reviews. Evidence-Based Child Health, 7 (5), 1363-1399.

Diamond, M.J. (1989). The cognitive skills model: An emerging paradigm for investigating hypnotic phenomena. In N.P. Spanos \& J.F. Chaves (Eds.), Hypnosis: The Cognitive-behavioral perspective (pp. 380-399). Buffalo, NY: Prometheus Books.

Edwards, L. Y., \& Edwards, C. L. (2010). Psychosocial treatments in pain management of sickle cell disease. Journal of the National Medical Association, 102 (11), 10841094.

Egner, T., Jamieson, G., \& Gruzelier, J. (2005). Hypnosis decouples cognitive control from conflict monitoring processes of the frontal lobe. Neuroimage, 27, 969-978.

Ferrando, M., Galdón, M. J., Durá, E., Andreu, Y., Jiménez, Y., \& Poveda, R. (2012). Enhancing the efficacy of treatment for temporomandibular patients with muscular diagnosis through cognitive-behavioral intervention, including hypnosis: A randomized study. Oral Surgery, Oral Medicine, Oral Pathology and Oral Radiology, 113 (1), 81-89. Aviable via http: //dx.doi.org/10.1016/j.tripleo.2011.08.020

Ferreira, A. (2009). Treatment of pain in burned children. Informe Médico, 11 (4), 237-242. 
Fine, C. G. (2012). Cognitive Behavioral Hypnotherapy for Dissociative Disorders. American Journal of Clinical Hypnosis, 54 (4), 331-352. Aviable via: http://dx.doi.org/10. 1080/00029157.2012.656856

Gaylord, S. A., Whitehead, W. E., Coble, R. S., Faurot, K. R., Palsson, O. S., Garland, E. L..., \& Mann, J. D. (2009). Mindfulness for irritable bowel syndrome: Protocol development for a controlled clinical trial. BMC Complementary and Alternative Medicine, 9, art. No. 24. Aviable via http://dx.doi.org/10.1186/1472-6882-9-24

Golden, B. A. (2002). A multidisciplinary approach to nonpharmacologic pain management. Journal of the American Osteopathic Association, 102 (9 Suppl 3), S1-5.

Hely, J. M., Jamieson, G. A., \& Dunstan, D. (2011). Smoking cessation: A combined cognitive behavioural therapy and hypnotherapy self-help treatment protocol. Australian Journal of Clinical and Experimental Hypnosis, 39 (2), 196-227.

Jensen, M. (2011). Hypnosis for chronic pain management workbook. New York: Oxford University Press.

Keefer, L., Kiebles, J. L., Martinovich, Z., Cohen, E., Van Denburg, A., \& Barrett, T. A. (2011). Behavioral interventions may prolong remission in patients with inflammatory bowel disease. Behaviour Research and Therapy, 49 (3), 145-150. Aviable via http://dx.doi.org/10.1016/j. brat.2010.12.005

Khan, K. A., \& Weisman, S. J. (2007). Nonpharmacologic Pain Management Strategies in the Pediatric Emergency Department. Clinical Pediatric Emergency Medicine, 8 (4), 240-247. Aviable via http://dx.doi.org/10.1016/j. cpem.2007.08.008

Koeser, L., Dobbin, A., Ross, S., \& McCrone, P. (2013). Economic evaluation of audio based resilience training for depression in primary care. Journal of Affective Disorders, 149 (1-3), 307-312. Aviable via http://dx.doi.org/10.1016/j.jad.2013.01.044

Koucky, E. M., Galovski, T. E., \& Nixon, R. D. V. (2012). Acute Stress Disorder: Conceptual Issues and Treatment Outcomes. Cognitive and Behavioral Practice, 19 (3), 437-450. Aviable via http://dx.doi.org/10.1016/j.cbpra.2011.07.002

Krakauer, S. Y. (2006). The two-part film technique empowering dissociative clients to alter cognitive distortions and maladaptive behaviors. Journal of Trauma and Dissociation, 7 (2), 39-57. Aviable via http://dx.doi.org/10.1300/ J229v07n02_04

Kuppenheimer, W. G., \& Brown, R. T. (2002). Painful procedures in pediatric cancer: A comparison of interventions. Clinical Psychology Review, 22 (5), 753-786. Aviable via http://dx.doi.org/10.1016/S0272-7358(02)00105-8

Kuttner, L. (2009). CBT and hypnosis: The worry-bug versus the cake. Contemporary Hypnosis, 26 (1), 60-64. Aviable via http://dx.doi.org/10.1002/ch.375

Li, A. L. K., Gomez, M., \& Fish, J. S. (2010). Effectiveness of pain management following electrical injury. Journal of
Burn Care and Research, 31 (1), 73-82. Aviable via http:// dx.doi.org/10.1097/BCR.0b013e3181cb8e94

Lupu, V. (2008). Cognitive-behavioral therapy in pathological gambling; A case analysis. Journal of Cognitive and Behavioral Psychotherapies, 8 (2), 269-277.

Lynn, S. J., Malakataris, A., Condon, L., Maxwell, R., \& Cleere, C. (2012). Post-traumatic Stress Disorder: Cognitive Hypnotherapy, Mindfulness, and Acceptance-Based Treatment Approaches. American Journal of Clinical Hypnosis, 54 (4), 311-330. Aviable via http://dx.doi.org/ 10.1080/00029157.2011.645913

Malhotra, R., \& Avidan, A.Y. (2012). Neurodegenerative disease and REM behavior disorder. Current Treatment Options in Neurology, 14 (5), 474-492. Aviable via http://dx.doi.org/10.1007/s11940-012-0194-5

McRobbie, H., Bullen, C., Glover, M., Whittaker, R., Wallace-Bell, M., \& Fraser, T. (2008). New Zealand smoking cessation guidelines. New Zealand Medical Journal, 121 (1276), 57-70.

Meyerson, J., \& Konichezky, A. (2011). Hypnotically induced dissociation (HID) as a strategic intervention for enhancing OCD treatment. American Journal of Clinical Hypnosis, 53 (3), 169-181.

Milling, L. S., \& Breen, A. (2003).Mediation and moderation of hypnotic and cognitive-behavioral pain reduction. Contemporary Hypnosis, 20 (2), 81-97.

Milling, L. S., Kirsch, I., Meunier, S. A., \& Levine, M. R. (2002). Hypnotic analgesia and stress inoculation training: Individual and combined effects in analog treatment of experimental pain. Cognitive Therapy and Research, 26 (3), 355-371. Aviable via http://dx.doi.org/10.1023/A:1016029028002

Milling, L. S., Levine, M. R., \& Meunier, S. A. (2003). Hypnotic enhancement of cognitive-behavioral interventions for pain: An analogue treatment study. Health Psychology, 22 (4), 406-413. Aviable via http://dx.doi. org/10.1037/0278-6133.22.4.406

Milling, L. S., Reardon, J. M., \& Carosella, G. M. (2006). Mediation and moderation of psychological pain treatments: Response expectancies and hypnotic suggestibility. Journal of Consulting and Clinical Psychology, 74 (2), 253-262. Aviable via http://dx.doi.org/10.1037/0022-006X.74.2.253

Milling, L. S., Shores, J. S., Coursen, E. L., Menario, D. J., \& Farris, C. D. (2007).

Response expectancies, treatment credibility, and hypnotic suggestibility: Mediator and moderator effects in hypnotic and cognitive-behavioral pain interventions. Annals of Behavioral Medicine, 33 (2), 167-178. Aviable via http://dx.doi.org/10.1007/BF02879898

Montgomery, G. H., Kangas, M., David, D., Hallquist, M. N., Green, S., Bovbjerg, D. H., \& Schnur, J. B. (2009). Fatigue during Breast Cancer Radiotherapy: An Initial Randomized Study of Cognitive-Behavioral Therapy Plus Hypnosis. Health Psychology, 28 (3), 317-322. Aviable via http://dx.doi.org/10.1037/a0013582 
Montgomery, G. H., Schnur, J. B., \& Kravits, K. (2013). Hypnosis for cancer care: Over 200 years Young. CA Cancer Journal for Clinicians, 63 (1), 32-44. Aviable via: http:// dx.doi.org/10.3322/caac.21165

Pekala, R. J., Maurer, R., Kumar, V. K., Elliott, N. C., Masten, E., Moon, E., \& Salinger, M. (2004). Self-hypnosis relapse prevention training with chronic drug/alcohol users: Effects on self-esteem, affect, and relapse. American Journal of Clinical Hypnosis, 46 (4), 281-297.

Perfect, M. M., \& Elkins, G. R. (2010). Cognitive-behavioral therapy and hypnotic relaxation to treat sleep problems in an adolescent with diabetes. Journal of Clinical Psychology, 66 (11), 1205-1215. Aviable via http://dx.doi. org/10.1002/jclp.20732

Richardson, K. M., \& Rothstein, H. R. (2008). Effects of Occupational Stress Management Intervention Programs: A Meta-Analysis Journal of Occupational Health Psychology, 13 (1), 69-93. Aviable via http://dx.doi. org/10.1037/1076-8998.13.1.69

Richardson, J., Smith, J. E., McCall, G., Richardson, A., Pilkington, K., \& Kirsch, I. (2007) Hypnosis for nausea and vomiting in cancer chemotherapy: A systematic review of the research evidence. European Journal of Cancer Care, 16 (5), 402-412. Aviable via: http://dx.doi.org/10.1111/ j.1365-2354.2006.00736.x

Rogers, J. (2006). Hypnosis: An adjunct to cognitive behavior therapy. Australian Journal of Clinical and Experimental Hypnosis, 34 (1), 65-70.

Rosenquist, S. E. (2013). When the Bough Breaks: Rethinking Treatment Strategies for Perinatal Depression. American Journal of Clinical Hypnosis, 55 (3), 291-323. Aviable via http://dx.doi.org/10.1080/00029157.2012.723284

Saps, M., \& Di Lorenzo, C. (2009). Pharmacotherapy for functional gastrointestinal disorders in children. Journal of Pediatric Gastroenterology and Nutrition, 48 (SUPPL. 2), S101-S103. Aviable via http://dx.doi.org/10.1097/ MPG.0b013e3181a15f49

Savard, J., Simard, S., Ivers, H., \& Morin, C. M. (2005). Randomized study on the efficacy of cognitive-behavioral therapy for insomnia secondary to breast cancer, part I: Sleep and psychological effects. Journal of Clinical Oncology, 23 (25), 6083-6096. Aviable via http://dx.doi. org/10.1200/JCO.2005.09.548

Shor, R., \& Orne, E. C. (1962). Harvard Group Scale of Hypnotic Susceptibility. Palo Alto, CA.: Consulting Psychologists Press.
Schnur, J., David, D., Kangas, M., Green, S., Bovbjerg, D., \& Montgomery, G. (2009). A randomized trial of a cognitive-behavioral therapy and hypnosis intervention on positive and negative affect during breast cancer radiotherapy. Journal of Clinical Psychology, 65 (4), 433-455. Aviable via http://dx.doi.org/10.1002/jclp.20559

Schnur, J. B., \& Montgomery, G. H. (2008). Hypnosis and cognitive-behavioral therapy during breast cancer radiotherapy: A case report American Journal of Clinical Hypnosis, 50 (3), 209-215.

Sebastiani, L., D’Alessandro, L., Menicucci, D., Ghelarducci, B., \& Santarcangelo, E. (2006). Role of relaxation and specific suggestion in hypnotize motional numbing. International Journal of Psychophysiology 63, 125-132.

Sim, J., \& Adams, N. (2002) Systematic review of randomized controlled trials of nonpharmacological interventions for fibromyalgia. Clinical Journal of Pain. 18 (5), 324-336.

Smith, B. (2011). Hypnosis continues to show promise in reducing pain and soothing anxiety, although the research is still inconclusive about its success in smoking cessation. Monitor on Psychology, 42 (1), 50-53.

Tan, G., Alvarez, J. A., \& Jensen, M. P. (2006).Complementary and alternative medicine approaches to pain management. Journal of Clinical Psychology, 62 (11), 14191431. Aviable via http://dx.doi.org/10.1002/jclp.20321

Tellegen, A. (1979). On measures and conceptions of hypnosis. The American Journal of Clinical Hypnosis, 21 (2 3), 219-37.

Tolin, D.F. (2009). Alphabet Soup: ERP, CT, and ACT for OCD. Cognitive and Behavioral Practice, 16 (1), 40-48. Aviable via http://dx.doi.org/10.1016/j.cbpra.2008.07.001

Walters, V. J., \& Oakley, D. A. (2006).Hypnotic imagery as an adjunct to therapy for irritable bowel syndrome: An experimental case report. Contemporary Hypnosis, 23 (3), 141-149. Aviable via http://dx.doi.org/10.1002/ ch.317

Weitzenhoffer, A. M., \& Hilgard, E. R. (1959). Stanford Hypnotic Susceptibility Scale Forms A \& B. Palo Alto, CA: Consulting Psychologists Press.

Weitzenhoffer, A. M., \& Hilgard, E. R. (1962). Stanford Hypnotic Susceptibility Scale, Form C. Palo Alto, CA: Consulting Psychologists Press.

Wiechman-Askay, S., Patterson, D. R., \& Sharar, S. R. (2009). Virtual Reality Hypnosis. Contemporary Hypnosis, 26(1), 40-47. Aviable via http://dx.doi.org/10.1002/ch.371 